\title{
DESAFIOS TEÓRICOS DA PSICOLOGIA MACROCULTURAL: ENTREVISTA COM CARL RATNER ${ }^{1}$
}

\author{
Sheila Daniela Medeiros dos Santos ${ }^{2}$ \\ Alessandra Oliveira Machado Vieira \\ Gisele Toassa \\ Fernando Lacerda Júnior \\ Universidade Federal de Goiás, Goiânia-GO, Brasil
}

\section{APRESENTAÇÃO}

Carl Ratner nasceu em 1943 em Nova York, EUA. Em 1964 graduou-se em Psicologia pela University of Wisconsin, em Madison, e em 1970 doutorou-se em Psicologia Social pela State University of New York, em Buffalo. Foi professor da Humboldt State University até se aposentar e desenvolveu atividades como professor visitante em diversas universidades dos EUA, da Arábia Saudita e da China. Atualmente, Ratner é professor visitante do Programa de Pós-Graduação em Psicologia da Universidad Autónoma de Morelos, no México, e diretor do Institute for Cultural Research and Education. Ratner é membro de diversas sociedades científicas, membro do comitê editorial de diversos periódicos (Culture \& Psychology, Teoría e Crítica de la Psicología e Forum: Qualitative Social Research) e autor de diversos livros, capítulos de livros e artigos publicados em periódicos que o consagram como um teórico de destaque no campo editorial no cenário acadêmico europeu, americano e asiático ${ }^{2}$.

Sua trajetória intelectual remonta aos anos de 1970, quando, a partir das propostas da antipsiquiatria, começou a discutir a necessidade de uma psicologia crítica (Ratner,
1967) e de se construir uma psicologia dialética (Ratner, 1971). Durante o seu percurso acadêmico coordenou diversos projetos de investigação estudando os trabalhos de Vigotski, Luria e Leontiev (Ratner, 1995) e os princípios epistemológicos da Psicologia Cultural (Ratner, 2002). A partir desses estudos, Ratner passou a argumentar que a Psicologia Cultural, apesar de ter surgido com 0 propósito de superar 0 biologicismo e o reducionismo psicológico, está, em seus desdobramentos mais atuais, desavisadamente, reproduzindo concepções subjetivistas (Ratner, 2006; 2012; 2014). Nesse contexto, Ratner propôs a construção de uma corrente na Psicologia Cultural enfatizando sua potencial contribuição para a promoção de processos de mudança social: a Psicologia Macrocultural (Ratner, 2006; 2012; 2014).

De acordo com Ratner, a Psicologia Macrocultural (PMC) é uma teoria geral da Psicologia que busca uma compreensão científica da psicologia humana, desvelando os seus determinantes culturais (Ratner, 2006; 2014). Para esse autor, a cultura não é apenas uma variável, mas é a base e o lócus do fenômeno psicológico (Ratner, 2012). Nessa linha, Ratner assevera que uma divisão da Psicologia em diversos setores, campos ou especialidades é desnecessária e até

1 Agradecemos a Eduardo Carli de Moraes e a Ludimila Gabriela Correa de Paula, pela colaboração voluntária com parte da transcrição e da tradução da entrevista.

2 Endereço para correspondência: Rua Dona Maria Umbelina Couto, 388, ap. 61, Bairro Taquaral - CEP 13.076-011 Campinas-SP, Brasil. E-mail: sheiladaniela@yahoo.com.br.

3 Para maiores informações sobre as publicações de Carl Ratner acessar: http://sonic.net/ cr2. 
indesejada: "A PMC é uma teoria científica geral que explica a natureza cultural dos fenômenos psicológicos" (2006, p. 133). Isto não significa que o autor rejeite teorias, pesquisas, teses e conceitos produzidos por diversas teorias psicológicas, mas que busca integrá-las em uma teoria psicológica geral.

Para Ratner (2006; 2012), a PMC busca, fundamentalmente, a mudança social. Sem transformar a cultura não é possível pensar qualquer possibilidade de provocar mudanças duradouras no processo de constituição dos fenômenos psicológicos. Em uma acepção mais precisa, a PMC possibilita a análise de processos psicossociais e enfatiza os fatores macroculturais (instituições sociais, artefatos e conceitos culturais) com a finalidade de criticar processos deletérios na sociedade contemporânea (Ratner, 2012; 2014).

A partir de tais considerações, a proposta de fazer uma entrevista com o pesquisador Carl Ratner se justifica, prioritariamente, pela necessidade de divulgar e aprofundar, no Brasil, um campo de estudos em expansão especificamente a partir dos anos 1990 nos Estados Unidos da América e na Europa: a Psicologia Cultural. A entrevista foi realizada no dia 06 de novembro de 2013, como parte de um conjunto de atividades propostas (minicursos, conferências, reuniões de trabalho) durante a visita de Carl Ratner à Faculdade de Educação da Universidade Federal de Goiás, no período de 05 a 08 de novembro de 2013. A entrevista seguiu um roteiro construído pelos professores Fernando Lacerda Júnior e Gisele Toassa. Já o trabalho de edição foi concretizado pelas professoras Sheila Daniela Medeiros dos Santos e Alessandra Oliveira Machado Vieira. Não poderíamos deixar de mencionar que durante o trabalho de transcrição e tradução contamos com a contribuição efetiva e primorosa de Eduardo Carli de Moraes (Mestre em FilosofiaUFG) e de Ludimila Correa de Paula (graduanda em Psicologia-UFG). Por fim, agradecemos a presença inestimável do Prof. Carl Ratner na Faculdade de Educação da Universidade Federal de Goiás, a disposição de conceder-nos a entrevista, de disponibilizar uma bibliografia de difícil acesso em nosso país e, sobretudo, de brindar-nos com a possibilidade de instituir um debate raro, provocativo e instigante acerca da PMC no Brasil.

\section{ENTREVISTA}

Qual a importância e a relevância da $\mathrm{PMC}^{4}$ para as ciências humanas contemporâneas?

A importância dessa abordagem está em compreender a relação da psicologia com a cultura. Por macrocultura entendo as instituições sociais, os artefatos e os conceitos culturais. A PMC estuda o fenômeno psicológico em relação aos fatores macroculturais, isto é, estuda como esses fatores dão origem, influenciam, constituem, socializam e objetivam a Psicologia. É um campo vasto e complexo e uma nova abordagem que relaciona o estudo da sociedade ao estudo da Psicologia. Penso que a PMC, além de ter implicações científicas importantes, por compreender a natureza da psicologia humana como parte da cultura, também apresenta consequências sociais e políticas para uma melhor compreensão da nossa sociedade, para a superação da alienação e para a elucidação do mundo em que vivemos. Então, penso que a PMC é um empreendimento vasto e instigante.

Quais são os principais fundamentos que sustentam o seu pensamento e os principais teóricos que marcaram a sua trajetória acadêmica e profissional no que diz respeito ao desenvolvimento da PMC?

Eu acredito que uma das maiores contribuições foi a de Vigotski e de sua teoria científica, a chamada Psicologia SócioHistórica ou Psicologia Histórico-Cultural. Vigotski pensa a Psicologia em termos culturais e históricos, o que é possível notar a partir do próprio nome da teoria, a qual se aproxima muito da abordagem teórica que desenvolvo. A produção de Vigotski é muito ampla, embora ele tenha vivido pouco. Vigotski foi, certamente, um dos maiores pensadores a influenciar-me. Em particular, uma das principais contribuições de Vigotski para o meu trabalho foi a de demonstrar como a psicologia é um fenômeno essencialmente cultural. Convém ressaltar que Vigotski não explorou muitos detalhes específicos sobre a

4 A palavra psicologia é usada por Ratner para se referir à ciência psicológica ou para se referir ao fenômeno psicológico. Aqui, "Psicologia" aparece com letra maiúscula quando Ratner refere-se à ciência e com letra minúscula quando Ratner referese ao fenômeno psicológico. 
macrocultura, pois focou mais a socialização familiar, o papel de educadores e a Psicologia do Desenvolvimento, embora o fundamental de seu pensamento seja a relação entre psicologia e aspectos culturais, históricos e sociais. Vigotski, especificamente, estudou a psicologia de acordo com os princípios do Materialismo Histórico do Marxismo. Por isso em todos os seus escritos há uma riqueza de informações e de conceitos que me ajudaram a desenvolver a PMC. Eu tive a possibilidade de ampliar conceitos específicos e de compreender a sociedade de modo mais abrangente, mas Vigotski não teve tempo para isso. Assim, esse autor foi influente porque indicou a relevância da cultura e porque desenvolveu uma teoria psicológica geral. Vigotski não apenas asseverou a importância da cultura, da forma como o fizeram, por exemplo, os antropólogos; ele desenvolveu uma teoria psicológica muito precisa, que possibilitou um grande avanço. Assim, o que eu procuro fazer é dar continuidade ao desenvolvimento do pensamento históricosocial e materialista-histórico de Vigotski.

Outro teórico importante que exerceu influência sobre o meu pensamento foi Urie Bronfenbrenner, um psicólogo russo da Psicologia do Desenvolvimento que viveu nos Estados Unidos. Bronfenbrenner também estava familiarizado com as ideias de Vigotski e por essa razão desenvolveu conceitos muito interessantes sobre os diferentes sistemas da sociedade. Bronfenbrenner introduziu a ideia de macrossistema da sociedade. Então, esse teórico pode ser considerado como outra influência relevante para o meu trabalho.

Outra influência fundamental foi a de antropólogos culturais, especificamente, os trabalhos sobre Antropologia Psicológica. Os antropólogos psicológicos estudaram a cultura concentrando-se em aspectos psicológicos e elaboraram diversos trabalhos sobre como a socialização das crianças ou as emoções se diferenciavam em culturas distintas. Neste sentido, a Antropologia Psicológica contribuiu muitíssimo, oferecendo informações específicas cruciais sobre a relação entre cultura e psicologia.

Houve, ainda, influências filosóficas. Uma das mais importantes foi a de Sartre, com o seu relevante trabalho "Crítica da razão dialética". Cumpre lembrar que esse trabalho é difícil de analisar, pois contém uma grande quantidade de informações e discussões sobre a natureza da cultura e a relação entre a psicologia e a cultura. É importante destacar, ainda, que Sartre, especialmente no prefácio intitulado "Questões de Método", discorre de forma intensa sobre o modo como entende a psicologia em relação à cultura e à história.

Por fim, os primeiros autores da Escola de Frankfurt também foram essenciais para o meu trabalho, uma vez que apresentam discussões muito interessantes sobre a natureza da cultura e da sociedade capitalista. Eu os considero fundamentais pelo fato de discutirem a cultura não apenas de forma abstrata, mas de forma concreta. Os teóricos da Escola de Frankfurt discorrem sobre as mudanças que ocorreram na cultura em relação ao capitalismo, à indústria cultural, à mídia e outros aspectos. Assim, estas são algumas das influências que fundamentaram o meu trabalho.

\section{Hoje em dia, no campo da psicologia, você tem} diálogo estabelecido com quais teóricos?

Eu estudei profundamente os trabalhos de Vigotski e através das minhas pesquisas estabeleci contato com importantes teóricos que também os estudaram. Eu me tornei muito amigo de René Van der Veer, o principal tradutor e intérprete de Vigotski. Particularmente, houve uma época em que nos aproximamos bastante, chegando até mesmo a conhecer a família e a visitar a casa um do outro. Por esse motivo nós estabelecemos um intenso diálogo. Van der Veer traduziu para o inglês o terceiro volume das Obras Completas de Vigotski e eu escrevi o prólogo desse trabalho. Nós trocamos diversas correspondências e, especialmente, foi possível contribuir com o seu trabalho corrigindo alguns de seus escritos na língua inglesa, pois apesar de Van der Veer ser fluente em inglês, sua nacionalidade é holandesa. Por isso nós temos uma boa amizade e uma relação acadêmica intensa. Então, pode-se dizer que eu mantenho proximidade com importantes vigotskianos. Cumpre assinalar que eu também fiz parte do conselho editorial da revista "Culture \& Psychology", e por esse motivo tenho muito contato com Valsiner e com todas as pessoas com ele envolvidas. Em meus escritos e em minhas publicações estabeleço ativas discussões com todos eles. Eu desenvolvi a PMC em uma direção específica, de um modo 
um pouco mais radical do que o fizeram outros psicólogos culturais. Afirmo isso porque grande parte dos psicólogos culturais não problematiza a possível articulação dos fundamentos teóricos da mesma maneira. Por exemplo, grande parte das pessoas não relacionam as ideias de Vigotski com a macrocultura. Há antropólogos e vigotskianos interessados em estudar a macrocultura, por isso dialogo com todos eles; no entanto, nem sempre nosso pensamento se desenvolveu da mesma forma.

A PMC destaca três fatores macroculturais: instituições sociais, artefatos e conceitos culturais. Por que você enfatiza esses três "macrofatores"? Como você os define e como você os selecionou?

Em parte, encontrei esses fatores macroculturais na teoria de Vigotski. Toda a ênfase na linguagem presente na obra desse teórico está, obviamente, relacionada aos conceitos culturais. Os antropólogos psicológicos também usam conceitos culturais com muita frequência. Por exemplo, suas explicações sobre emoções e a socialização das crianças estão relacionadas com a forma como as diferentes culturas conceituam crianças, adultos, privacidade ou comunidade. Por isso, a partir de certas leituras encontrei alguns elementos e percebi que seria importante chegar a uma definição específica de cultura, porque muitas definições eram muito abstratas ou incompletas. Então, basicamente, foi a partir dessas fontes que eu selecionei esses fatores. Por exemplo, os artefatos são muito discutidos por Vigotski e pelos teóricos da atividade e eu usei essas fontes como ponto de partida para a minha obra. Fundamentalmente, o meu desejo era criar uma definição específica de cultura a partir de elementos fundamentais que estavam sendo usados por outros autores.

Você falou muito sobre Vigotski. Você se definiria como vigotskiano? Se sim, como você relaciona a PMC com o trabalho de Vigotski? E, ainda, você acredita que a PMC se desenvolve dando continuidade à obra de Vigotski ou há, de acordo com o seu ponto de vista, uma superação?

Eu diria que estou desenvolvendo o trabalho de Vigotski. Eu penso que Vigotski estava ciente das especificidades da cultura. Ele era um defensor da revolução russa e da sociedade socialista russa e acreditava que essa era a chave para estudar e transformar a psicologia humana. Vigotski tinha diversas preocupações políticas. Neste sentido, escreveu artigos em que abordou o modo como o capitalismo empobreceu a psicologia humana e como a transformação socialista enriqueceria a psicologia humana. Então, Vigotski certamente elaborou temas que abordo atualmente. Esses elementos estão em sua obra e são mencionados em quase todos os seus escritos, embora alguns não tenham sido desenvolvidos por ele, possivelmente por falta de tempo. Desse modo, estou procurando aprofundar esses elementos e também estou tentando especificar qual é a natureza da cultura capitalista e qual poderia ser a natureza cultural de uma alternativa socialista. Então eu acredito que os aspectos fundantes da PMC estão em Vigotski e eu os estou desenvolvendo. Eu também atribuo importância a Vigotski pelo fato de possuir uma teoria psicológica. Afirmo isso porque dificilmente um autor interessado em reforma social foi capaz de criar uma teoria psicológica. Certamente Martin Baró possui uma teoria psicológica, mas esta não se compara à profundidade da teoria psicológica de Vigotski. A teoria de Vigotski pode ser considerada uma ciência psicológica que se caracteriza por uma perspectiva essencialmente social. Eu penso que essa questão é muito mais interessante intelectualmente, afinal, não basta simplesmente uma pessoa dizer que conhece pessoas, que é possível mudar a sociedade e que é necessário encontrar meios para torná-la mais democrática. Obviamente isso é verdade, mas acredito que é algo realmente fácil de dizer e que não há nisso nada de intelectualmente interessante. Agora, se é possível compreender que a Psicologia pode contribuir para esse tipo de desenvolvimento, ou seja, para empreender de fato uma mudança social e especificar algumas direções para isso, então creio que isso é algo realmente interessante. É por isso que acredito que Vigotski é tão importante, afinal eu não conheço nenhum outro autor que possua uma teoria que se preste à transformação social da maneira como o faz a teoria de Vigotski.

Por falar em transformação social, você considera que há relações entre o Marxismo e PMC?

Eu acredito que a PMC também está desenvolvendo o Marxismo no campo psicológico. É interessante pensar que a PMC está aprofundando as ideias de Vigotski em um sentido mais cultural, social e político, porque ele 
não teve tempo para fazer isso e apenas indicou o caminho. Marx, por sua vez, teve uma brilhante e profunda compreensão da sociedade e da transformação social. Então eu penso que a PMC desenvolve a teoria desses dois autores em direções complementares.

Você acredita que a PMC pode ser útil para criticar perspectivas teóricas contemporâneas multiculturalistas?

Bem, particularmente, acredito que sim. Esta questão é complicada e controversa, porque muitas pessoas pensam que o multiculturalismo é a solução para a opressão social. Penso que o multiculturalismo não possui uma crítica profunda sobre a sociedade capitalista predominante. Na verdade, essa perspectiva enfatiza que há diferentes grupos na sociedade capitalista com costumes particulares com os quais muito podemos aprender. Acredito que há alguma verdade nisso, mas uma verdade muito limitada, porque esses grupos multiculturais no capitalismo, ou mesmo em países socialistas, também são grupos oprimidos, ou seja, sua psicologia não está livre da opressão. Assim, um grupo oprimido aprender com outro é algo limitado, porque não se rompe o ciclo da opressão.

Grupos oprimidos não superaram as estruturas sociais básicas da opressão e também não superaram as estruturas psicológicas da opressão. Então, a visão multicultural é muito limitada em sua descrição e crítica ao capitalismo. Eu acredito que não devemos criticar o capitalismo tomando como referência o que ocorre com determinados grupos culturais como, por exemplo, os índios na Amazônia. É necessário desenvolver uma crítica social e política do macrossistema. Os multiculturalistas não são realmente psicólogos macroculturais, pois não estão lidando com o macrossistema da cultura. Penso que a crítica realizada pelos multiculturalistas é muito limitada, embora pareça ser uma crítica que vai além do status quo. Por isso se pode afirmar que os multiculturalistas vão além do status quo de um grupo apenas para cair no status quo de outro grupo.

Considerando a PMC nos dias atuais, o que você poderia nos dizer sobre as pesquisas mais recentes e os principais desafios teóricos? $\mathrm{E}$, ainda, qual será a sua próxima pesquisa no campo?

As pesquisas mais recentes que desenvolvi a partir da PMC aparecem na Enciclopédia de
Psicologia Crítica editada por Thomas Teo (2014), na qual há cinco verbetes de minha autoria: PMC, Falsa Consciência, Emancipação, Capitalismo e Psicologia da Opressão. Na pesquisa em questão eu procurei trabalhar aspectos políticos da cultura e da psicologia de modo mais intenso. Além disso, atualmente estou estudando mais cuidadosamente o trabalho de Foucault. Eu penso que a análise que esse autor faz da cultura é muito importante pelo fato de enfatizar aspectos como a política e o poder. Convém ressaltar que os psicólogos culturais geralmente não abordam esses aspectos, embora seus estudos sejam, indubitavelmente, relevantes para outros cientistas sociais.

Dos estudos de Foucault, também considero realmente fundamental para a PMC a noção governamentabilidade, isto é, a forma como a cultura organiza a subjetividade das pessoas e os modos de subjetivação. Essas ideias destacam a relevância dos aspectos políticos da cultura para a psicologia. Então, é nessa direção que pretendo dar continuidade às pesquisas: enfatizar os aspectos políticos da cultura, com a finalidade de mostrar como a política forma a cultura e como a psicologia é política em sua origem e em seu funcionamento. Se a psicologia tem uma base política, isso significa que possui uma função política ao apoiar o sistema que a constituiu. Isso faz com que a psicologia seja analisada como um importante fenômeno cultural e político.

Outro elemento essencial a ser mencionado está relacionado àquilo a que nos referimos como Psicologia da Opressão. Neste sentido, se a psicologia é formada pela cultura política e esta é constituída por aspectos opressivos, então temos que identificar tais aspectos para não apenas compreender a psicologia, mas para transformála. Isso nos leva à discussão e elaboração de uma Psicologia da Libertação ou uma psicologia emancipatória, pois, se a psicologia humana é oprimida, isto é, se as pessoas são oprimidas, então como podemos ignorar os aspectos opressivos da cultura ao desenvolver intervenções e reformas sociais que objetivam contribuir para enriquecer a Psicologia? Apesar de estas questões serem muito simples nos dias de hoje, é realmente interessante ver como podem ser desenvolvidas e conceituadas dentro do campo da Psicologia de forma que esta possa efetivamente contribuir para a compreensão da cultura e do mundo atual. 
Qual a sua visão sobre a Psicologia Cultural? Você considera sua perspectiva uma abordagem diferente dela?

Há dois grupos de psicólogos culturais. Um grupo é constituído por antropólogos psicológicos, que estudam profundamente a cultura e mostram como a psicologia muda junto com ela; no entanto, o problema é que eles não dispõem de uma teoria psicológica. Fazem descobertas muito interessantes sobre a relação entre questões psicológicas e culturais, mas realmente não possuem uma teoria que explique por que essas coisas existem. Esta é uma diferença. Por outro lado, temos os psicólogos culturais psicologistas e alguns teóricos da atividade que, por exemplo, publicam [no periódico] Culture \& Psychology. Eles não possuem uma teoria social boa e abrangente, pois não falam sobre o capitalismo, não analisam o capitalismo. Por isso estas abordagens são bem diferentes da PMC.

Existem vários experimentos na Psicologia Social nos EUA, como os de Stanley Milgram, Zimbardo, etc. Como você compreende, analisa e estuda essa Psicologia Social? Que relações você estabelece entre a PMC e a Psicologia Social? Você se considera um psicólogo social?

Sim. Na verdade, meu doutorado é em Psicologia Social. A Psicologia Social hegemônica (mainstream Social Psychology) não estuda a cultura e muito menos com Vigotski. Vigotski não é parte do campo da Psicologia Social e eles não precisam da noção de cultura. Psicólogos sociais realizam microexperimentos. Há, como você mencionou, o estudo de Milgram ou o experimento da Prisão de Stanford, que são muito interessantes e indicativos de certas coisas; mas você tem que adicionar um quadro de análise cultural para esses estudos. Por exemplo, os estudos de Milgram e os estudos da prisão de Stanford não falam sobre as razões culturais para o comportamento das pessoas, então fazem parecer que essas razões são uma tendência natural, como se as pessoas naturalmente se conformassem à autoridade. Bem, em primeiro lugar, claro que isso não é verdade. Se você traz uma perspectiva cultural, compreende a sociedade em que as pessoas viviam, e isto ajuda a compreender as razões reais para aqueles comportamentos; mas os psicólogos sociais não compreendem as razões, atribuem-nas às disciplinas naturais. Assim, eu acredito que praticamente todas as principais correntes da psicologia hegemônica lidam com pessoas vivendo em uma determinada cultura e sendo por esta influenciada, mas os psicólogos sociais não estudam esse contexto: eles estudam apenas o comportamento das pessoas e em seguida o atribuem a algum processo psicológico. Então, acho que essa é a grande diferença entre a Psicologia Social e a Psicologia Cultural. Os psicólogos sociais realmente deveriam se desenvolver em direção à Psicologia Cultural, porque isso ajudaria a entender melhor por que as pessoas, nos citados experimentos, agem de uma dada maneira. Por isso, neste sentido, eu não sou um psicólogo social, pois eles não querem dar esse passo. Eu dei esse passo e, por isso, considero a maior parte das pesquisas da Psicologia Social não muito informativas, porque mostram como as pessoas agem em certas situações, mas não há um real entendimento do porquê de agirem assim.

Algumas pessoas diriam que esse seria um passo da Psicologia Social Psicológica para uma Psicologia Social Sociológica. Você concorda com isso?

Certamente seria um passo de
distanciamento do que os primeiros estão fazendo, mas, como disse Vigotski, se você entende a cultura, entende a psicologia bem melhor. Então esse é o problema com o campo da Psicologia. Para eles, a psicologia se restringe ao comportamento das pessoas, eles não veem o comportamento das pessoas como parte da cultura. Acham que se você introduzir a cultura está deixando a psicologia, eliminando-a ou negando-a; mas, do meu ponto de vista, isto é falso. Isto ajudaria a entender melhor a psicologia e, como eu disse, a entender muito mais profundamente os experimentos sobre conformidade. Os psicólogos sociais não compreendem por que os seus sujeitos se comportam daquela forma. Apenas dizem "deixenos em paz, queremos continuar fazendo Psicologia do jeito que sempre fizemos e focar o individual. Não nos importamos com a cultura, e se você se importa, não pode ser um psicólogo".

Como você responderia à seguinte afirmação: "A PMC não é nada mais que uma crítica da teoria psicológica baseada em um entendimento sociológico e, então, não seria uma Psicologia propriamente dita, porque não está focada nos indivíduos"?

(Risada). Eu acredito que isso é completamente falso. O que estou enfatizando no meu trabalho é a importância da teoria psicológica, e é por isso que acho Vigotski tão 
importante. Li todas as teorias psicológicas sobre emoções, Psicologia do Desenvolvimento, doenças mentais e tudo mais. Não estou simplesmente criticando-os, dizendo "nós deveríamos jogar fora a Psicologia". Isto é o que eles dizem: "se você nos criticar, a partir da perspectiva da cultura, então você não é um psicólogo". Discordo e considero isso uma loucura, pois estão definindo a Psicologia de um modo muito restrito e dizendo que, se você quer mudar a definição de psicologia, não pode ser um psicólogo.

Então, como você definiria, teórica e epistemologicamente, o objeto da Psicologia? Qual seria a diferença entre a Psicologia e outras ciências humanas?

Eu acho que a especialidade da Psicologia é focar os processos que nós chamamos de psicológicos. É meio arbitrário, mas acredito que os psicólogos tenham dado uma importante contribuição à identificação de questões psicológicas como, por exemplo, as emoções. Este é um fenômeno muito interessante e foram os psicólogos que realmente estudaram as emoções, assim como outros assuntos, tais como as doenças mentais, o desenvolvimento da criança e a Psicologia do Desenvolvimento. Todas essas são importantes questões que os psicólogos trouxeram à baila. Então, acho que a psicologia é um campo muito útil e os psicólogos culturais podem manter esse foco. É isto o que diferencia a Psicologia Cultural, por exemplo, da Sociologia. Esta última está mais preocupada com as estruturas sociais, estruturas de classes, ocupações, distribuição de renda e o modo como as instituições são formadas. Estas questões também são relevantes, mas eles não focam especificamente a emoção, a doença mental, a Psicologia do Desenvolvimento ou outras questões. Então, considero que a Psicologia é importante para tratar daquelas áreas que têm sido o foco tradicional da Psicologia, mas a maneira como buscam compreender essas questões é problemática, pois não consideram a cultura. Então, proponho pegarmos essas questões identificadas pelos psicólogos e trazêlas à vida real das pessoas, à cultura das pessoas. É por isso que compreendo a PMC como ciência psicológica. Acho que a Psicologia é a PMC. Os psicólogos ficariam horrorizados em ouvir isso, porque dizem: "Não, você nem é um psicólogo, nós somos os verdadeiros psicólogos". Eu respondo: "Não, eu sou o psicólogo de verdade". Reconheço as suas contribuições, mas acredito que precisam levar sua disciplina para um âmbito cultural.

Nos últimos anos você começou a falar de PMC afirmando que houve, no campo da Psicologia Cultural, uma contrarrevolução. Por isso você fala da PMC tentando manter um potencial crítico e um quadro específico de análises para a Psicologia Cultural, certo?

Sim.

Como evitar que essa contrarrevolução ocorra na PMC? Como evitar que a PMC se torne funcionalista $e$ se distancie de análises marxistas, etc.?

Como podemos evitar? Tendo bons colegas como o professor Fernando (risos). Quero dizer, não há como evitar. Sabemos que se as pessoas querem destruir a PMC, elas podem (risos). $O$ que posso fazer é elaborar princípios o mais claramente possível. Eu vejo que as pessoas mais interessadas nisso são aquelas que compartilham uma perspectiva social crítica, que acreditam em transformação social. Isto é, na verdade, uma questão acadêmica interessante. Acho que o campo da Psicologia irá mudar e que as pessoas não se interessarão pela Psicologia Cultural, a menos que desenvolvam uma perspectiva política diferente, porque há muita política na Psicologia Cultural. Se você não considera a política importante, também não achará a PMC relevante, e então dirá que isso é irrelevante para a psicologia; mas, esperançosamente, conforme o mundo entre em colapso, as pessoas se interessarão mais por mudanças sociais, serão mais críticas do status quo político e verão que a PMC pode contribuir para o movimento político.

Como os fundamentos da PMC podem contribuir, como base teórica, para pesquisas e estudos em Psicologia Educacional e Escolar?

Bem, eu não sou um especialista em Educação ou em Psicologia da Educação, mas certamente há princípios da PMC a serem aplicados. Eu diria que o primeiro passo é entender a natureza político-cultural da Educação. Eu tenho feito muitas pesquisas sobre o desenvolvimento da educação neoliberal nos Estados Unidos e é um processo realmente fascinante. Um processo totalmente político, 
iniciado por ricos capitalistas. Bill Gates, por exemplo, é uma grande figura da educação neoliberal e da privatização da Educação. Eu acho que devemos começar olhando para a natureza político-cultural da Educação e como esta é estruturada por esse sistema cultural e político. A crítica da Educação incluiria a crítica da política cultural, que vai além da Educação. Eu não penso que a Educação pode ser melhorada por algum processo educacional restrito a esse campo. Em minha opinião, a única maneira de entender e melhorar a Educação é olhar para fora, para a macrocultura, isto é, para aquilo que está estruturando a Educação e é a causa dos problemas da Educação. A solução não é achar um processo educacional que possa resolver estes problemas, mas sim, trabalhar no sentido de identificar e mudar as fontes desses problemas macroculturais. Esta seria a perspectiva geral.

Nas universidades brasileiras enfrentamos muitos desafios para oferecer cursos e desenvolver programas que relacionam Psicologia e Cultura em uma perspectiva crítica. Geralmente os programas de graduação são mais baseados em Freud, Skinner Rogers, somente em psicólogos tradicionais. Essa perspectiva é a mais comum também em programas de pós-graduação. Talvez esta seja a mesma situação que você encontra nos EUA. Como você acha que esse tipo de desafio pode ser enfrentado e superado? Como você enfrentou esse desafio durante a sua trajetória?

Em minha trajetória, de certa forma, tive sorte, porque quando comecei a ensinar, estavam ocorrendo as mudanças políticas que caracterizaram os anos 1960 e 1970 nos EUA. É como aqui, no Brasil, onde você tem mais oportunidades de ensinar certos cursos por causa de mobilizações políticas que abriram alguns espaços. Quando comecei a dar aula, introduzi cursos como bases culturais da Psicologia e coisas assim. No começo tive mais liberdade para desenvolver alternativas, porque não estava em uma universidade de elite dos EUA, então não houve muita pressão para eu publicar nos periódicos hegemônicos (mainstream journals). Penso que estar em uma universidade maior é um obstáculo grande para desenvolver Psicologia Cultural, porque eles o forçam a publicar suas pesquisas de acordo com o que é dominante. Não há tempo para sentar por alguns anos, escrever críticas que são publicadas em periódicos menores, escrever livros e coisas assim. Neste sentido tive muita sorte e acho que você também, pois essa não é uma universidade de elite. Então, a primeira coisa que devemos fazer é criar um espaço onde se possam desenvolver estes temas, e uma vez feito, criar cursos... De fato, há no Apêndice deste livro (Macro Cultural Psychology: A Political Philosophy of Mind) uma proposta curricular para a Psicologia Cultural. Penso que nenhuma universidade vai permitir um programa inteiro de Psicologia Cultural. A única maneira de isso acontecer é Bill Gates dar uns milhões de dólares e dizer "ok, implemente esse programa". Então, tudo é uma questão de desenvolver o máximo de cursos que você puder, isto é, conseguir realizar pelo menos alguns cursos que incluam essa perspectiva. Além disso, tal perspectiva não precisa estar sozinha. Quando eu era professor e dava aula de Psicologia Social, sempre dedicava a metade do tempo para os estudos tradicionais e a outra metade para discutir Psicologia Transcultural (Cross-cultural Psychology) e Psicologia Cultural. É uma grande luta, pois você tem que entender que está meio sozinho e não terá muito apoio. É preciso encontrar apoio em si mesmo, em amigos e colegas, seus amigos ricos dos EUA (risos), e assim produzir o máximo que puder. Além disso, eventualmente ainda pode desenvolver um periódico dedicado a isso e começar a atrair pessoas de outros países, traduzir para o português e talvez até começar uma associação brasileira. Há várias associações internacionais, como a International Association of Cross Cultural Psychology. Pode-se também propor alguns simpósios na conferência deles e apresentar a perspectiva brasileira, suas pesquisas e teorias. Outra organização importante que lida com teoria da atividade é a International Society for Cultural and Activity Research. Acho que a perspectiva deles é um pouco diferente da $P M C$, pois não desenvolvem uma abordagem macrocultural no estudo da atividade, mas - é claro - eles têm bases em Vigotski. É possível organizar seus próprios pontos de vista e pesquisas e quando houver congressos participar e atrair algumas pessoas. Penso que você não encontrará pessoas que concordem totalmente com você, mas poderá encontrar pessoas, pelo menos, abertas para ouvir você. Por meio de publicações, trabalhos, associações e pelo colapso do mundo capitalista ocidental pode ser aberto um caminho. 
Muito obrigado pelo seu tempo. Você gostaria de dizer algo mais para nosso registro? Ou fora dele?

Para o registro? Sim, eu amo o Brasil!

\section{REFERÊNCIAS}

Ratner, C. (1967). The critical psychology of R. D. Laing. Telos, 5, 98-114.

Ratner, C. (1971). Principles of dialectical psychology. Telos, 9, 83-109.

Ratner, C. (1995). A Psicologia sócio-histórica de Vygotsky: aplicações contemporâneas (Trad: L. L. Oliveira). Porto Alegre: Arte Médicas.

Ratner, C. (2002). Cultural Psychology: Theory and method. New York: Plenum Press.
Ratner, C. (2006). Cultural Psychology: A perspective on psychological functioning and social reform. Mahwah: Lawrence Erlbaum Associates.

Ratner, C. (2012). Macro Cultural Psychology: A political philosophy of the mind. Oxford: Oxford University Press.

Ratner, C. (2014). Macro Cultural Psychology. Em T. Teo (org.), Encyclopedia of Critical Psychology (pp. 10951111). New York: Springer.

Sheila Daniela Medeiros dos Santos: mestre e doutora em Educação pela Universidade Estadual de Campinas, docente do Programa de Pós-Graduação em Psicologia da Universidade Federal de Goiás, Brasil.

Alessandra Oliveira Machado Vieira: mestre em Psicologia pela Universidade de Brasília, doutora em Psicologia do Desenvolvimento Humano pela mesma universidade, professora adjunta na Universidade Federal de Goiás, Brasil.

Gisele Toassa: mestre em Educação pela Universidade Estadual Paulista, doutora em Psicologia Escolar e do Desenvolvimento Humano pela Universidade de São Paulo, docente do Programa de Pós-Graduação em Psicologia da Universidade Federal de Goiás, estágio pós-doutoral no Program of History and Theory of Psychology, York University, Canadá.

Fernando Lacerda Júnior: doutor em Psicologia como Profissão e Ciência na Pontifícia Universidade Católica de Campinas, coordenador do Programa de Pós-Graduação em Psicologia da Universidade Federal de Goiás, Brasil. 